\title{
Transitional dispersive scenarios driven by mesoscale flows on complex terrain under strong dry convective conditions
}

\author{
J. L. Palau ${ }^{1}$, G. Pérez-Landa ${ }^{2}$, and M. M. Millán ${ }^{1}$ \\ ${ }^{1}$ Fundación Centro de Estudios Ambientales del Mediterráneo (CEAM), València, Spain \\ ${ }^{2}$ Environmnental Department, Iberdrola Ingenieria y Construcción, Madrid, Spain
}

Received: 12 March 2008 - Published in Atmos. Chem. Phys. Discuss.: 5 June 2008

Revised: 24 November 2008 - Accepted: 1 December 2008 - Published: 8 January 2009

\begin{abstract}
By experimentation and modelling, this paper analyses the atmospheric dispersion of the $\mathrm{SO}_{2}$ emissions from a power plant on complex terrain under strong convective conditions, describing the main dispersion features as an ensemble of "stationary dispersive scenarios" and reformulating some "classical" dispersive concepts to deal with the systematically monitored summer dispersive scenarios in inland Spain. The results and discussions presented arise from a statistically representative study of the physical processes associated with the multimodal distribution of pollutants aloft and around a 343-m-tall chimney under strong dry convective conditions in the Iberian Peninsula. This paper analyses the importance of the identification and physical implications of transitional periods for air quality applications. The indetermination of a transversal plume to the preferred transport direction during these transitional periods implies a small (or null) physical significance of the classical definition of horizontal standard deviation of the concentration distribution.
\end{abstract}

\section{Introduction}

The objective of this study is to describe, by experimentation and modelling, the atmospheric dispersion of the emissions from a power plant situated on very complex terrain in inland Spain under typical summer conditions. This is a representative study of how emissions from a tall chimney are distributed aloft in a multimodal way around it (with no clear

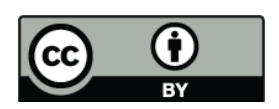

Correspondence to: J. L. Palau (jlp@confluencia.biz) mean plume advective direction during transitional periods, as documented between different, but concatenated, dispersive scenarios). The experimental data used were extracted from the "Els Ports-Maestrat" database (Palau et al., 2006), and the field campaign analysed in this paper was identified as one of the most recurrent summer dispersive scenarios in the area, which have been monitored since 1994 (Palau, 2003).

In spring and summer, when anticyclonic conditions dominate over the Iberian Peninsula, with low winds $(<6 \mathrm{~m} / \mathrm{s})$, strong insolation $\left(>800 \mathrm{~W} / \mathrm{m}^{2}\right)$ and frequent formation of the Iberian Thermal Low (ITL), tropospheric flow regimes are governed by mesoscale processes (Millan, 1991; Millan et al., 1997). In the late eighties, using simultaneous dispersion data from four tall chimneys located around the entire Iberian Peninsula, Millan et al. (1991) documented that under conditions of ITL formation there is a net convergence of air towards the interior from the different coastal areas. The development of the ITL during the day forces the surfacewind flows to merge into several major convergence lines, which become locked to the main orographic features inland (Millan et al., 2000). In this period, the daily breeze cycles, coupled with up-slope winds, drive the air masses over the entire territory. Thus, as a consequence of these main meteorological processes and the relevant scales interacting in (and among) the different airsheds in the Peninsula (i.e., coupling between local and non-local processes), dispersive conditions present a marked diurnal cycle.

With respect to the representativeness of these kinds of mesoscale forcings, results from European research projects aimed at characterising the dynamics of pollutants in the Western Mediterranean Basin (WMB) have documented that during the warm season diurnal cycles in the flow regime

Published by Copernicus Publications on behalf of the European Geosciences Union. 
represent a typical pattern in the region (Millan et al., 1997). Moreover, results from the EU-funded MECAPIP and RECAB projects (Millan et al., 1997) showed that the Thermal Low over the Iberian Peninsula acquires a quasipermanent character from May to September and constitutes the most frequent surface meteorological situation in this region (Palau et al., 2005).

The thermally-driven wind-field structure (turbulence intensity, wind direction and speed, etc.) varies according to the diurnal evolution of the heating of the different mountain slopes (depending on their orientation with respect to the sun). On complex terrain, this yields progressive and continuous variations in the dispersive conditions in the lower troposphere, making it necessary for us to adopt the concept of "transitional period", which in this study refers to the time period between two "stationary" dispersive scenarios. A "stationary dispersive scenario" refers to a low tropospheric wind-field structure that remains constant during a certain period of time. But, considering that no thermodynamic variable can be assumed to "remain constant" with time (mainly because of the stochastic nature of atmospheric dynamics), we prefer to use the term "quasi-stationarity" in this paper and, thus, to identify the "transitional periods" as periods of time between clearly different "quasi-stationary" dispersive scenarios.

In this study, we identify a quasi-stationary dispersive scenario by direct comparison with another quasi-stationary dispersive scenario: When any dispersive condition (e.g., nocturnal drainage flows) remains essentially the same but is essentially different from another one at the same spatial location but at a different time (e.g., thermally-driven diurnal circulations), we identify a transitional period between them. This paper analyses the importance of the identification and physical implications of these transitional periods for air quality applications.

The power plant selected, with a 343-m-tall chimney, is located in the Northeast of the Iberian Peninsula and the plume is affected by the diurnal cycle of the wind flow. Wintertime dispersive conditions in the region have been described (Palau et al., 2006) using the same methodology as in this paper for calculating of the pseudo-Lagrangian horizontal dispersion values of the measured and simulated plume aloft.

This paper is structured in six sections; following the introduction, section two deals with the description of the methodology used. Section 3 focuses on the description of the main results, first analysing them from a qualitative point of view and then describing the statistics obtained when comparing simulated results with measurements. Section 4 is the discussion section, where we focus on a dynamic description of the typical summer dispersion pattern in the region, which is far removed from the classical point of view for a dispersive scenario. To end the paper and summarise the main results and discussions, we have included a brief conclusions section.

\section{Methodology}

For this study, we have chosen a dispersive scenario considered representative of the region under summer conditions (Palau, 2003). To describe it we have focused on a three-day campaign obtained from the "Els Ports-Maestrat" database (detailed information on this database can be found in http://www.ceam.es, and in Palau et al., 2006). The "Els Ports-Maestrat" database, sponsored by the Environment Department of the Valencia (Spain) Regional Government, consists of an ensemble of field campaigns conducted systematically and periodically at the South-western border of the Ebro basin (Spain) since November 1994. One of the main objectives of these field campaigns is to monitor (aloft and on the ground) the $\mathrm{SO}_{2}$ plume emitted from the $343 \mathrm{~m}$-tall chimney of the Andorra Power Plant (APP) located at Teruel $\left(00^{\circ} 22^{\prime} 46^{\prime \prime} \mathrm{W} ; 40^{\circ} 59^{\prime} 54^{\prime \prime} \mathrm{N}\right)$.

This study focuses on the $\mathrm{SO}_{2}$-plume tracking carried out for 3 days in the summer of 1995 by means of a vehicle equipped with a COSPEC (optical COrrelation SPECtrometer) and a pulsed fluorescence $\mathrm{SO}_{2}$ analyser. The COSPEC passive remote sensor utilises solar radiation to obtain $\mathrm{SO}_{2}$ concentration distribution measurements aloft and around the emission source (Millan et al., 1976); its response is proportional to the vertically-integrated $\mathrm{SO}_{2}$ concentration (throughout the optic path between infinity and the instrument telescope). The fast-response $\mathrm{SO}_{2}$ analyser records the ground-level (over the roof of the vehicle) $\mathrm{SO}_{2}$ concentration distribution along the trajectory followed by the vehicle around the power plant. Thus, by using both instruments at the same time, $\mathrm{SO}_{2}$ concentrations at ground level and aloft can be measured simultaneously.

Our plume-tracking strategy consisted of making transects, as transversal as possible to the mean plume-transport direction, at different distances from the chimney (Palau et al., 2006) to record the diurnal evolution of the dispersive conditions around the power plant. Our method of obtaining typical horizontal deviations of the plume distribution aloft from the available experimental records has already been described in the literature (Millán et al., 1976; Millán, 1978); moreover, the details of the modified PseudoLagrangian method used in this study can be found in Palau et al. (2006). Nevertheless, we should point out that the experimental measurements of the $\mathrm{SO}_{2}$ distribution aloft, followed by the above referenced procedure, allow us to obtain mean values of the transversal plume dispersion at different distances from the emission point and during a determinate temporal period.

To help with the interpretation of the experimental records during the selected summer campaign, we used a nonhydrostatic mesoscale meteorological model MM5 (Grell et al., 1994) coupled to a Lagrangian Particle Dispersion (LPD) Model FLEXPART (Stohl et al., 2005). Similar modelling scheme, but employing RAMS as mesoscale model and HYPACT as LPD, has proved useful to understand the complex 


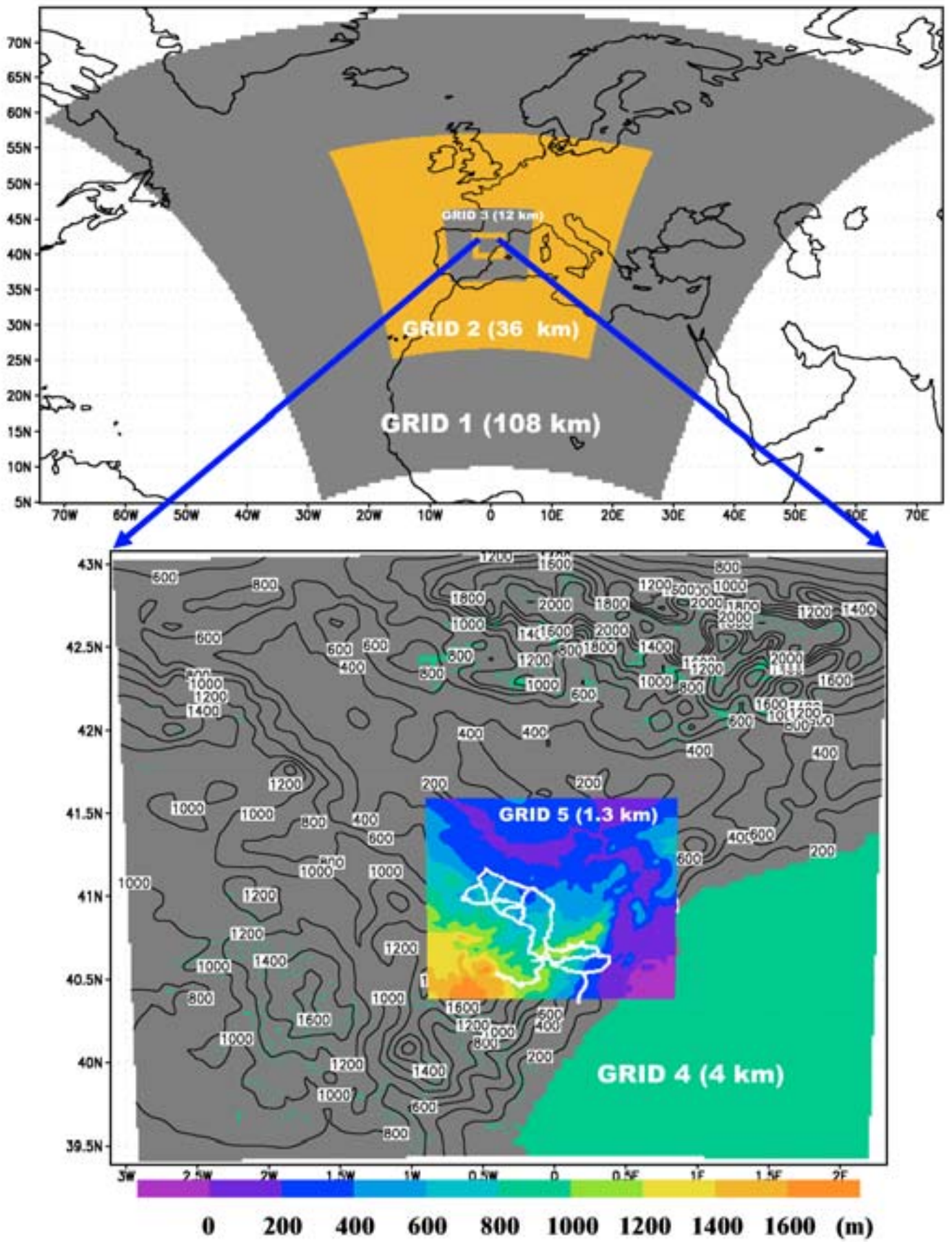

Fig. 1. Topography and geographical location of domains for the meteorological model. The road network used to measure the plume distribution with the COSPEC is indicated by the white line in grid 5.

sequence of non-stationary scenarios during the development of thermal circulations in a nearby coastal region (PérezLanda et al., 2007a and b; Palau et al., 2005).

The mesoscale model was configured (Fig. 1) using five nested domains $(100 \times 100$ grids spaced at $108,36,12,4$ and $1.3 \mathrm{~km}$, respectively) centred over the Andorra power plant. Thirty-nine sigma levels were configured, with a $10 \mathrm{~m}$ spacing near the surface increasing gradually up to $1000 \mathrm{~m}$ near the model top at $15000 \mathrm{~m}$ above ground level (m a.g.l.), fifteen of them defined within the first $1500 \mathrm{~m}$ a.g.l. The MM5 predicts the wind components $u, v$ and $w$, the temperature, the humidity, the pressure perturbation and the turbulence parameters. Planetary Boundary Layer is parameterised following Blackadar's nonlocal closure (Zhang and 
Table 1. Dispersive results. Start.: Starting time of the measurements; Finish.: Finishing time of the measurements; Dist.: Distance to the chimney; Exp. Disp.: Experimental dispersion; Sim. Disp.: Simulated dispersion for each plume-rise scheme. Boldface numbers correspond to transitional periods in the wind and turbulence fields.

\begin{tabular}{cccccccc}
\hline Day & Start & Finish & Dist $(\mathrm{Km})$ & $\begin{array}{c}\text { Exp. Disp. } \\
(\mathrm{Km})\end{array}$ & $\begin{array}{c}\text { Sim. Disp. } \\
\text { Briggs }(\mathrm{Km})\end{array}$ & $\begin{array}{c}\text { Sim. Disp. } \\
700 \mathrm{~m}(\mathrm{Km})\end{array}$ & $\begin{array}{c}\text { Sim. Disp. } \\
450 \mathrm{~m}(\mathrm{Km})\end{array}$ \\
\hline $25 / 07$ & $09: 50$ & $11: 30$ & 6.07 & 0.79 & 1.31 & 1.24 & 1.16 \\
$25 / 07$ & $16: 17$ & $16: 54$ & 15.49 & 0.92 & 2.79 & 3.05 & 2.55 \\
$25 / 07$ & $17: 24$ & $17: 54$ & 15.06 & 1.41 & 3.04 & 2.82 & 2.53 \\
$26 / 07$ & $07: 15$ & $08: 49$ & 9.97 & 1.89 & 1.24 & 1.30 & 0.95 \\
$26 / 07$ & $08: 57$ & $09: 17$ & 9.94 & 1.96 & 2.38 & 2.19 & 1.77 \\
$26 / 07$ & $09: 25$ & $10: 06$ & 19.14 & 4.63 & 5.48 & 5.58 & 5.27 \\
$26 / 07$ & $10: 47$ & $11: 35$ & 13.15 & $\mathbf{1 . 7 8}$ & $\mathbf{3 . 9 5}$ & $\mathbf{4 . 5 8}$ & $\mathbf{4 . 3 6}$ \\
$26 / 07$ & $16: 35$ & $18: 00$ & 9.03 & $\mathbf{2 . 1}$ & $\mathbf{6 . 4 5}$ & $\mathbf{1 1 . 9}$ & $\mathbf{9 . 8 0}$ \\
$27 / 07$ & $17: 09$ & $18: 20$ & 8.42 & $\mathbf{1 . 9 7}$ & $\mathbf{4 . 2 0}$ & $\mathbf{8 . 7 4}$ & $\mathbf{1 1 . 8}$ \\
\hline
\end{tabular}

Anthes, 1982). Four-dimensional data assimilation (Stauffer and Seaman, 1994) was applied to the mother domain nudging toward the gridded $2.5^{\circ}$ resolution NCEP Reanalysis (Kalnay et al., 1996). Albedo, roughness and available humidity vary according to the USGS (US Geological Survey) land-use database.

The LPD model takes into account wind velocity variances and Langrangian autocorrelations. The spread of the pollutant is simulated by the Langevin equation derived by Thomson for inhomogeneous Gaussian turbulence under non-stationary conditions (McNider et al., 1988). Turbulence statistics are obtained by using the Hanna scheme with some modifications taken from Ryall and Maryon for convective conditions (Stohl et al., 2005). The autocorrelation coefficient is assumed to be an exponential function that depends on the Lagrangian time scale. The time step used to move particles in the Markov chain model has to be variable in inhomogeneous turbulence and depends on the Lagrangian time scale (Uliasz, 1994). Well-mixed profiles can be obtained as long as the timestep is small enough to resolve the small-scale turbulence in the vicinity of the boundaries (Hurley and Physick, 1991). Like the mesoscale model, the LPD model was configured with USGS land-use data.

In our simulations, we treated the buoyant plume of the power plant by releasing particles following three different plume-rise schemes, at an effective chimney heights of 450 and $700 \mathrm{~m}$ and following Briggs (1975) plume-rise equations for hot plumes. The particles were released randomly within a $10 \times 10 \times 100 \mathrm{~m}$ volume at the start of the test simulations: $10 \times 10 \mathrm{~m}$ corresponds (broadly) to the diameter of the chimney exit. We chose a vertical distribution of $100 \mathrm{~m}$ to represent the distribution of the plume rise around the estimated effective high for the release $(50 \mathrm{~m}$ above and $50 \mathrm{~m}$ below the estimated constant highs of 450 and $700 \mathrm{~m}$ and the variable highs calculated following the Briggs plume-rise scheme).
The total amount of particles released was high $\left(2 \times 10^{6}\right)$, as we need high precision in the calculations of the horizontal dispersion of the simulated plume. This fact and the high resolution of the meteorological simulation used a large amount of computer power (the equivalent of 6 days of CPU time on a $3 \mathrm{GHz}$ local lab-top computer). However, optimising the modelling setup for AQ-forecasting purposes (e.g., 10\% of the particles might be enough) would allow two-day forecasts to be made in $12 \mathrm{~h}$ on a current labtop computer.

\section{Results}

Lagrangian dispersive simulations have been executed following three different plume rise schemes to avoid eventual interferences with the results obtained. The main results described herein, and the discussions presented in the following section, are not significantly influenced by uncertainties derived from the plume-rise scheme chosen (Tables 1 and 2, and Fig. 7).

The first plume rise scheme is based on the Briggs equations for hot plumes (Briggs, 1975), and the other two follow a "constant-height scheme", i.e., based on the final plume height after thermalisation (effective chimney height). The thermalisation heights for the "constant height schemes" were estimated by considering the minimum and maximum values obtained from the empirical (visual) observations recorded during the three-day field campaign.

\subsection{Qualitative description}

Comparison between measured and simulated dispersion results (Figs. 4 and 5, and also the supplementary material: http://www.atmos-chem-phys.net/9/119/2009/ acp-9-119-2009-supplement.pdf) shows that the coupled model (MM5+FLEXPART) is able to reproduce the main dynamical and dispersive features of the measured plume aloft. 
Table 2. Statistical skills for the horizontal dispersion values simulated with the three different emission schemes (450 m, $700 \mathrm{~m}$ and Briggs). The nomenclature for the different columns is: m: fitting slope; b: ordinate (in kilometres); SE: Standard Error (for both the fitting slope and the ordinate, in kilometres; p-value (for both the fitting slope and the ordinate); RMSE: Root Mean Squared Error (in kilometres); RMSEu: Unsystematic Root Mean Squared Error; RMSEs: Systematic Root Mean Squared Error; RMSEa: Additive Root Mean Squared Error; RMSEp: Proportional Root Mean Squared Error; RMSEi: Interdependence Root Mean Squared Error; d: Index of Agreement.

\begin{tabular}{lcccccc}
\hline & $\mathrm{m}$ & $\mathrm{b}(\mathrm{km})$ & $\mathrm{SE}(\mathrm{m})$ & $\mathrm{SE}(\mathrm{b})(\mathrm{km})$ & $\mathrm{p}$-value $(\mathrm{m})$ & $\mathrm{p}$-value $(\mathrm{b})$ \\
\hline $450 \mathrm{~m}$ & 0.91 & 0.61 & 0.32 & 0.75 & 0.048 & 0.461 \\
$700 \mathrm{~m}$ & 0.92 & 0.92 & 0.34 & 0.78 & 0.052 & 0.303 \\
BRIGGS & 0.90 & 0.97 & 0.32 & 0.74 & 0.049 & 0.262 \\
& & & & & & \\
& RMSE $(\mathrm{km})$ & RMSEu & RMSEs & RMSEa & RMSEp & RMSEi \\
$450 \mathrm{~m}$ & 0.95 & 0.83 & 0.45 & 0.61 & 0.21 & -0.46 \\
$700 \mathrm{~m}$ & 1.16 & 0.86 & 0.77 & 0.92 & 0.19 & -0.54 \\
BRIGGS & 1.14 & 0.82 & 0.78 & 0.97 & 0.24 & -0.62 \\
& & & & & & $\mathrm{~d}$ \\
$450 \mathrm{~m}$ & 0.77 & 0.23 & 0.42 & 0.05 & -0.24 & 0.88 \\
$700 \mathrm{~m}$ & 0.56 & 0.44 & 0.63 & 0.03 & -0.22 & 0.84 \\
BRIGGS & 0.52 & 0.48 & 0.73 & 0.04 & -0.29 & 0.84 \\
\hline
\end{tabular}

On the first day, from a synoptic point of view (Fig. 2), high pressures dominated most of Central Europe and the Western Mediterranean, although meteorological conditions over the northern half of the Iberian Peninsula were conditioned by the passage of a low-pressure system over the Cantabrian Sea. In the first hours of the day, a sixty meter-tall meteorological tower located near the power plant recorded NW winds, which later veered from East to South during the morning until the afternoon (Fig. 3). Following the longitudinal passage of a Low pressure system to the East (not shown), the morning Southeast winds in the Ebro valley turned to the Southwest in the afternoon, changing the plume transport direction aloft. This change in direction is correctly simulated by the model. Plume fumigations on the ground are well-correlated with the mean integral advection of the plume aloft, and both measurements and simulations show low level concentrations North of the power plant (see animation: http://www.atmos-chem-phys.net/9/ 119/2009/acp-9-119-2009-supplement.pdf).

On the second day, when the Low on the Cantabrian Sea migrated to the NE, a ridge of high pressure arrived at the Iberian Peninsula favouring the development of thermally driven mesoscale processes during the daytime (Fig. 2). During the early morning, when diurnal circulations were not yet developed, measurements showed down-valley drainage winds flowing towards the Mediterranean sea and advecting the plume aloft Southeastwards from the power plant, decoupled from the ground (Figs. 3 and 5). Afterwards, in association with mesoscale circulations activation and development, in the afternoon the wind veered, blowing from the Northeast (Figs. 3 and 5). With solar heating, mesoscale circulations began to affect the behaviour of the plume until its "mean integral advection" finally turned to the SW of the power plant. A relevant feature during the transitional period ${ }^{1}$ (from $11: 00 \mathrm{~h}$. to $15: 00 \mathrm{~h}$.) is that while the plume-axis aloft (defined by the centre of gravity of the $\mathrm{SO}_{2}$ distribution aloft) had a SW-NE direction, the mean integral advection of the plume was directed towards NW from the power plant (Fig. 8 and see animation: http://www.atmos-chem-phys.net/9/119/ 2009/acp-9-119-2009-supplement.pdf). During this transitional period, plume fumigations on the ground were completely decoupled from the location of the "new" (recently emitted) plume aloft (Figs. 5 and 6). Measurements and simulations (Figs. 5 and 6) are in good agreement showing the old parts of the plume aloft much more diluted (with lower concentrations) than the new ones. The simulations reproduced the transitional period of the dispersive conditions (although with a significant delay of two-to-three hours) but showed significant biases with ground-level concentration records. On the last day, the High was centred over the Cantabrian Sea and a Thermal Low formed in the South of the Iberian Peninsula driving mesoscale circulations in the study region (Fig. 2). The wind direction measured at the 60-m-tall tower (Fig. 3) shows a squared-shaped temporal evolution, typical of thermally-driven winds oscillating between West-Northwest and Northeast. The measured low-speed southern nocturnal flow is coherent with the concentration distribution recorded by the COSPEC (very wide shape near the chimney). This agrees with the scarce transport simulated during a 6 -h period by the model. At noon the direction of the plume is not well-defined, although both measured and simulated results show a slight trend towards the SE. In the evening the plume is again conditioned by

\footnotetext{
${ }^{1}$ In this context, we consider transitional period as the period of time during the plume-reorganisation phase.
} 

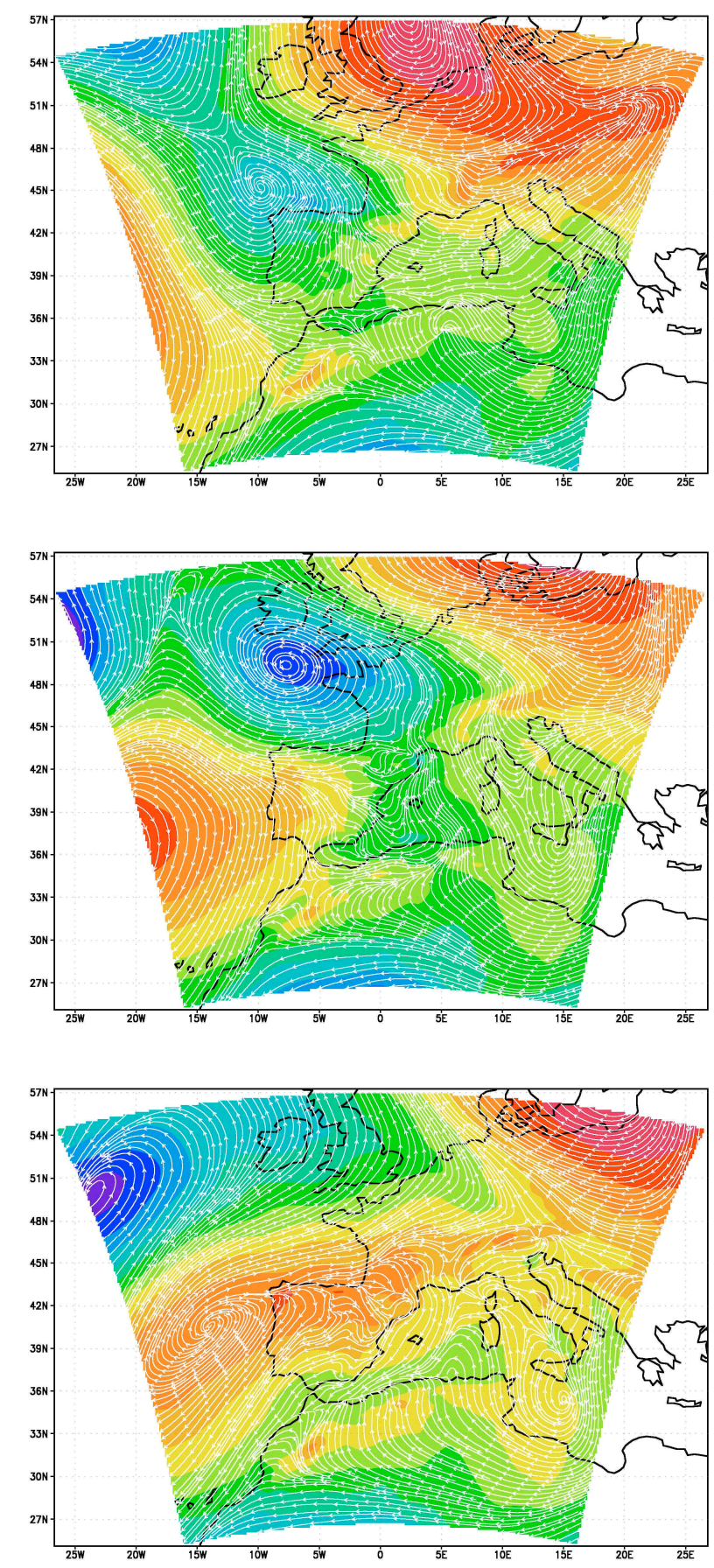

GrADS: COLA/GES

Fig. 2. Three synoptic weather charts including the pressure field and the wind streamlines simulated at $10 \mathrm{~m}$ above ground level at 06:00 h. UTC for (top) $25 \mathrm{July,} \mathrm{(middle)} 26 \mathrm{July}$, and (bottom) 27 July 1995.

the ITL development, turning towards the SW, as can be seen in the simulation and in the experimental measurements (see animation: http://www.atmos-chem-phys.net/9/ 119/2009/acp-9-119-2009-supplement.pdf).
Due to the low wind speed and the strong insolation (maximum value of total radiation, $878 \mathrm{~W} / \mathrm{m}^{2}$ at Morella station, $45 \mathrm{~km}$ Southeast the power plant) intense convective turbulence fumigates the $\mathrm{SO}_{2}$ plume very near the chimney $(<5 \mathrm{~km})$, and high concentrations are measured and simulated.

\subsection{Quantitative description}

Independently of the plume rise scheme followed, if we compare the experimental and simulated horizontal dispersion of the plume for equivalent time periods (Table 1 and Fig. 7), we find three measurements, corresponding to the central hours of the day and the afternoon, with discrepancies higher than 200\%. These discrepancies (bold numbers in Table 1) correspond to days characterised by dispersive scenarios with transitional periods in the wind and turbulence fields. These diurnal transitional periods between dispersive scenarios are typified (in dispersive terms) by the lack of a well-defined plume axis, or mean transport direction (Fig. 5 and animation: http://www.atmos-chem-phys. net/9/119/2009/acp-9-119-2009-supplement.pdf). The consequent indetermination of the transversal plume to the preferred transport direction implies a small (or null) physical significance of the classical definition of horizontal standard deviation of the concentration distribution (that is defined from the transversal axis to the average transport direction), whether this distribution is measured with the COSPEC, simulated with a dispersion model or parameterised through different schemes and approximations implemented in some dispersion models. Thus, to fit the experimental and simulated values of the horizontal dispersion, we have not considered values associated with transitional periods.

The simulated horizontal dispersions during "steady" dispersive periods fitted well (index of agreement (Willmott, 1981) between $84 \%$ and $88 \%$, Table 2) with observations (Fig. 7). During these dispersive periods, no major differences were found when calculating the simulated horizontal dispersion from the three different plume-rise schemes (Table 1). Nevertheless, from a statistical point of view, there is a clear dependence between the emission scheme used and the systematic and unsystematic contribution to the total mean square error (Table 2). Following a constant 450-m height scheme we found that the systematic contribution to the total mean square error is $23 \%$, while following the other two schemes the systematic contributions are $44 \%$ and $48 \%$. This difference in the amount of the systematic error contribution was interpreted as an indicator that the 450-m scheme better represents the measured dispersive conditions than the other two schemes. 


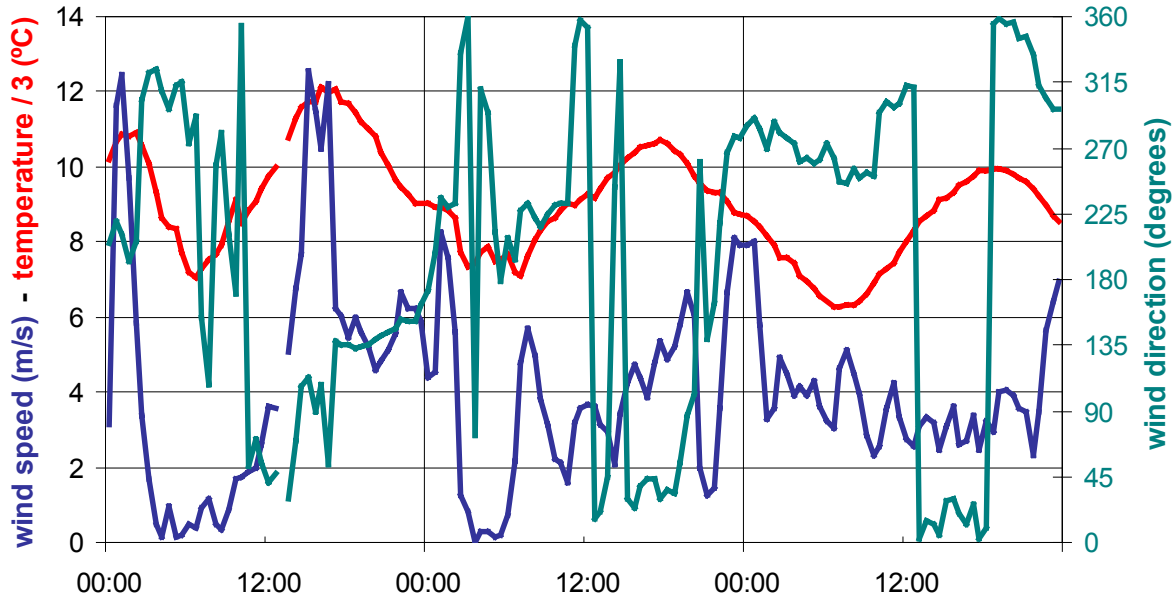

Fig. 3. Meteorological records during the field campaign. Red line, temperature at $10 \mathrm{~m}$ a.g.l. divided by three; blue line, wind speed at $60 \mathrm{~m}$ above ground level; green line, wind direction at $60 \mathrm{~m}$ a.g.l.

The magnitudes of total mean square errors are acceptable considering that, during this field campaign, the empirical errors associated with the measuring procedure were around $1 \mathrm{~km}$.

Analysis of the fitting statistics shows that all three plumerise schemes have similar statistical significances for horizontal turbulent diffusion. The slope of the linear regression between measurements and simulated values has $p$-values of about 0.05 , although the intersection value has low statistical significance $(>0.05)$. The index of agreement corroborates that, from a statistical point of view, the coupled models (MM5+FLEXPART) reproduce at least $84 \%$ of the observed variation.

\section{Discussion}

As in the case study described herein, bimodal distributions of the power plant plume have been systematically measured in this region under summer conditions since the eighties, with the mean direction of the integral advection of the plume aloft (orange vector in Fig. 8) being almost perpendicular to the axis defined by the centre of mass of the plume distribution aloft (green line in Fig. 8) and with high spatial heterogeneities of the fumigation field near the emission source. We have identified this type of dynamics during diurnal transitional periods associated with the reorganisation of the tropospheric wind field due to the progressive enhancement/lessening of the thermally driven wind circulations along the day. Thermal mesoscale tropospheric flows of this kind are simulated by MM5 as a physical consequence of the simulated exchanges of energy and water between the vegetation (or soil) and the atmosphere, which are directly dependent on the land-use defined on each grid-point and the initialisation of the model. The authors have found this to be the main reason for the significant delay of two-to-three hours with ground-level concentration records, when simulating the transitional periods of the dispersive conditions. This delay has been attributed to the configuration of the model and, more specifically, to the limitations in either the implemented parameterisation of the PBL in the meteorological model or the land-use database used in the FLEXPART model, or both. On the one hand, Blackadar's nonlocal closure scheme is based on the assumption that turbulent mixing is isotropic (i.e., symmetric) in the PBL; however, from observational evidence and large-eddy simulation modelling studies (Schumann, 1989), it is well-known that mixing processes in a convective boundary layer are essentially asymmetric (i.e., turbulence is anisotropic). On the other hand, surface cover-type classification system is responsible for heterogeneous surface fluxes of sensible and latent heat. Furthermore, our simulations show significant spatial biases with ground-level concentration records. Despite the model resolution, under stable dispersion conditions (plume advected as a ribbon-type plume), limitations on the model performance have been evidenced due to the local nature of plume impacts far away from the chimney $(>50 \mathrm{~km})$. Under such dispersion conditions slight deviations between the real and the simulated plume advective direction have a strong impact when comparing the simulated and measured local ground-level concentrations. Previous results (Palau et al., 2006, 2008) showed how on this complex terrain area, under stable dispersion conditions (nighttime), the simulated mechanical turbulence leeward of the mountains reproduces highly concentrated $\mathrm{SO}_{2}$ fumigations on the ground more than $60 \mathrm{~km}$ away from the power plant but with significant spatial biases associated with the local nature of the fumigations. Besides, under convective activity, an isotropic ground-level concentration field is simulated within a circular area with a radius of $20 \mathrm{~km}$ around 


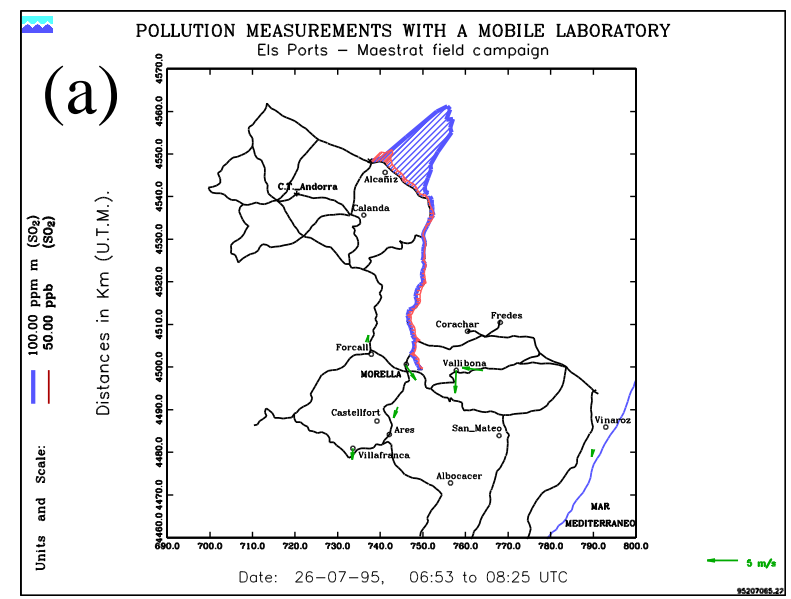

\section{SIMULATION TIME 8 UTC}

(c)

(e)
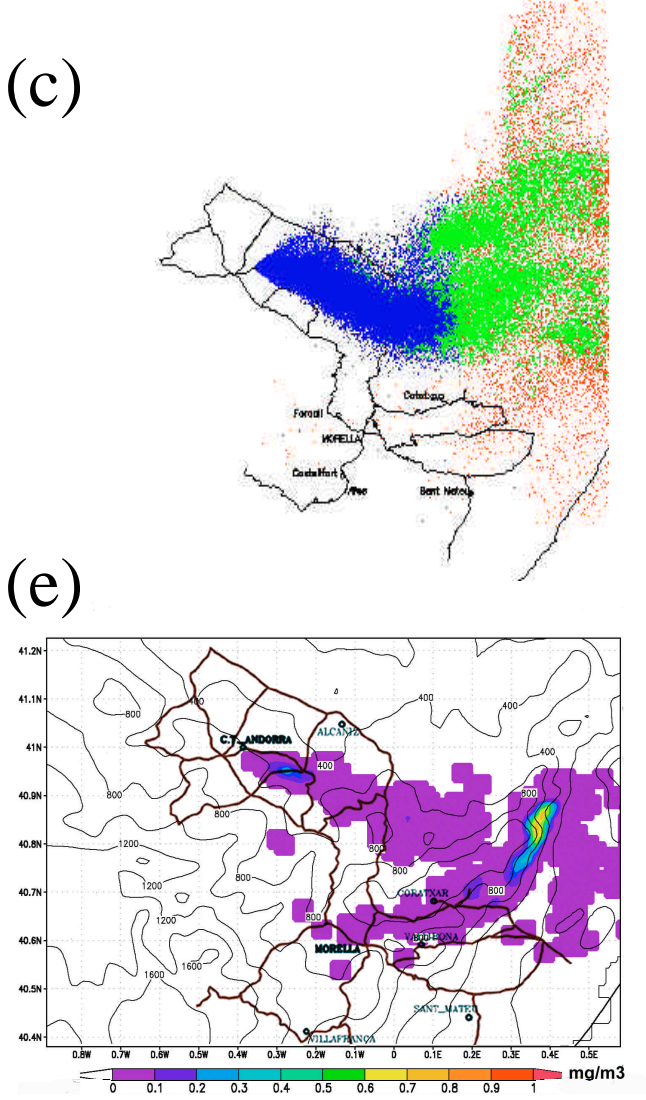

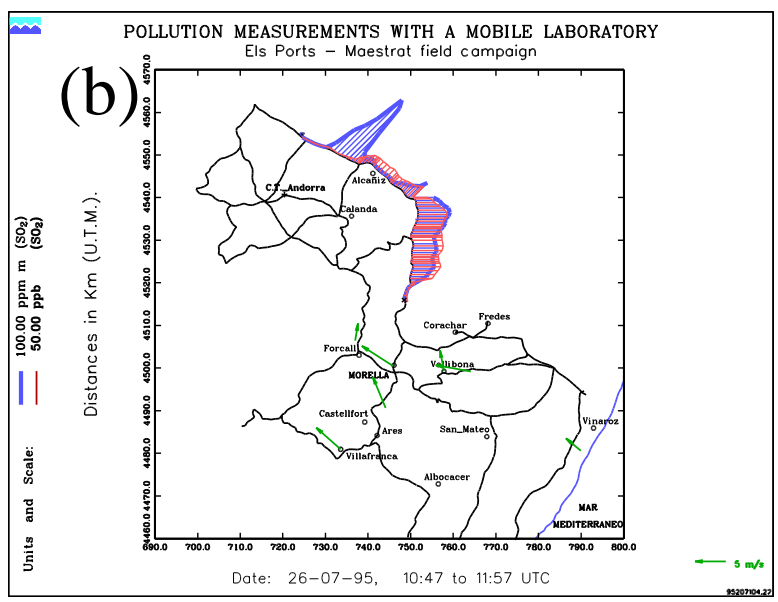

SIMULATION TIME 13 UTC

(d)

(f)

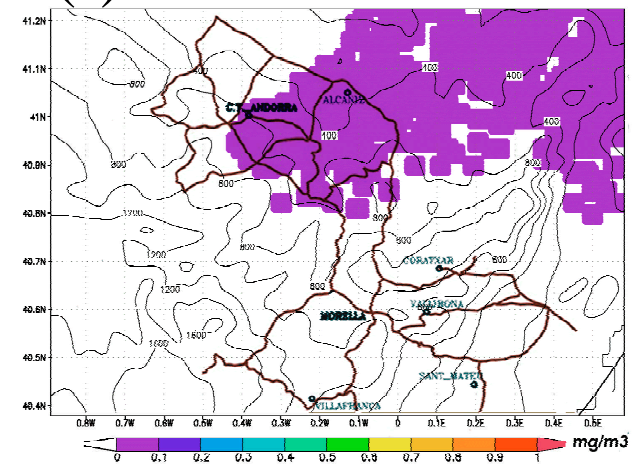

Fig. 4. Sequence of the experimental and simulated distributions for day 2 (morning). Correspondence between simulated outputs and experimental measurements (vertically integrated $\mathrm{SO}_{2}$ concentration) was determined from equivalent time periods. Representations are presented on the road network. Top (a, b) Experimental measurements (in blue, $\mathrm{SO}_{2}$ distribution aloft; in red, simultaneous $\mathrm{SO}_{2}$ concentrations on the ground); (a 06:53-08:25 UTC; b 10:47-11:57 UTC). Middle (c, d) Simulated plume aloft at 08:00 UTC (left) and 13:00 UTC (right); particles in colour scale indicate up to 2 (blue), 4 (green) and 6 (orange) h since emission. Bottom (e, f) Simulated $\mathrm{SO}_{2}$ ground-level concentrations (fumigations) at 08:00 UTC (left) and 13:00 UTC (right). 

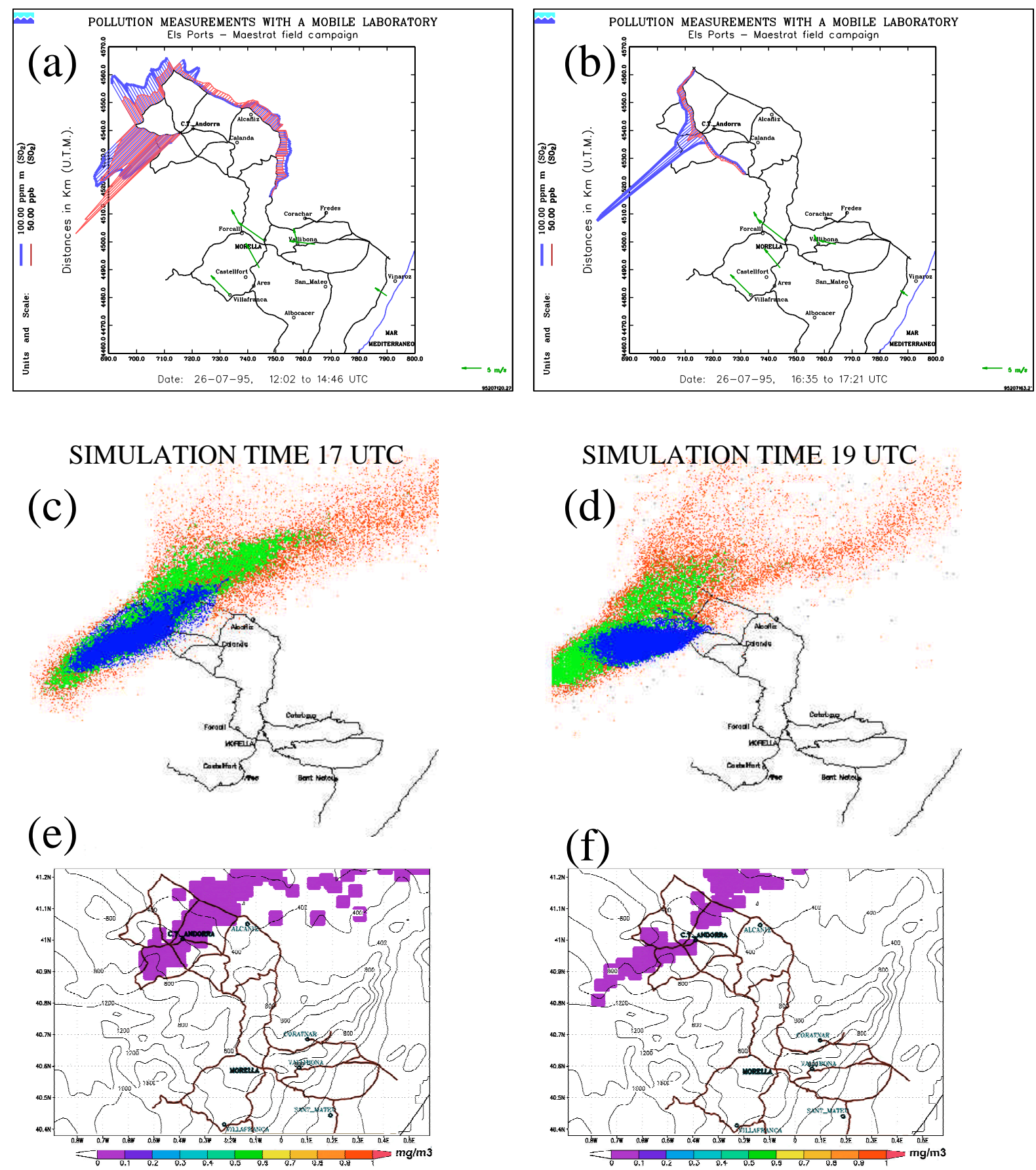

Fig. 5. Sequence of the experimental and simulated distributions for day 2 (afternoon). Correspondence between simulated outputs and experimental measurements (vertically integrated $\mathrm{SO}_{2}$ concentration) was determined from equivalent time periods. Representations are presented on the road network. Top (a, b) Experimental measurements (in blue, $\mathrm{SO}_{2}$ distribution aloft; in red, simultaneous $\mathrm{SO}_{2}$ concentrations on the ground); (a 12:02-14:46 UTC; b 16:35-17:21 UTC). Middle (c, d) Simulated plume aloft at 17:00 UTC (left) and 19:00 UTC (right); particles in colour scale indicate up to 2 (blue), 4 (green) and 6 (orange) h since emission. Bottom (e, f) Simulated $\mathrm{SO}_{2}$ ground-level concentrations (fumigations) at 17:00 UTC (left) and 19:00 UTC (right). 


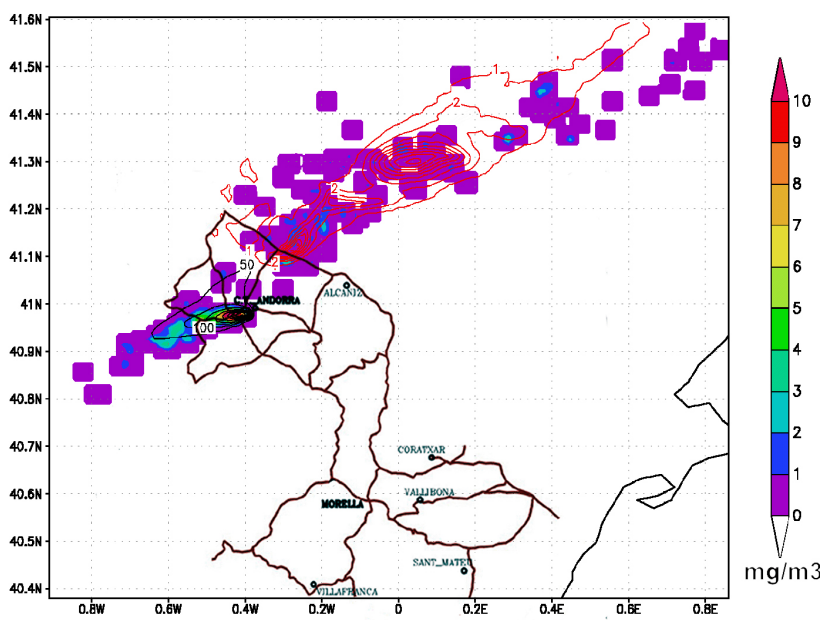

Fig. 6. Simulated vertical plume distribution above the road network around the power plant, at 17:00 UTC for day 2. Shaded colors indicate pollutant concentrations within the first $10 \mathrm{~m}$ a.g.l. Black contour lines indicate pollutant concentration aloft (integrated from 30 to $2700 \mathrm{~m}$ a.g.1.). Red contour lines indicate total pollutant concentration over $3000 \mathrm{~m}$ a.g.l. All magnitudes (contour lines and color palette) are expressed in $\mathrm{mg} / \mathrm{m}^{3}$.

the power plant; i.e., under summer conditions plume fumigations near the chimney are essentially equiprobable all around the chimney. A detailed analysis of these issues, disaggregating the accumulated plume footprints into the contributions of the different turbulent regimes activated in the MM5 PBL-parameterisation throughout the 3-day simulation (convective mixing and mechanical turbulence schemes), can be found in Palau et al. (2008). Analysis of the experimentally measured integral advection of the bi-modal distributions of the plume aloft gives rise to the necessity to reformulate some "classical" dispersive concepts to deal with typical dispersive scenarios under summer conditions in this region. Driven by mesoscale forcings, summer dispersive conditions here do not fit "classical" dispersive scenarios, in the sense of describing the main dispersion features as an ensemble of "stationary dispersive scenarios". On the contrary, from late spring to the beginning of autumn, the typical diurnal dispersive scenario in this mid-latitude complex terrain is a complex (synergetic) addition of different, continuously evolving, non-stationary (but concatenated) dispersive scenarios (Palau, 2003). Moreover, with respect to plume impacts on the ground, we need to distinguish between morning and late-afternoon transitional periods.

During the morning, transitional periods can last from one to several hours, as the thermal circulations strengthen the mesoscale forcings over a progressively hotter ground. This process favours the convective activity reaching the plume aloft, fumigating $\mathrm{SO}_{2}$. These are the classical "Hewson fu-

\section{Dispersion (Km)}

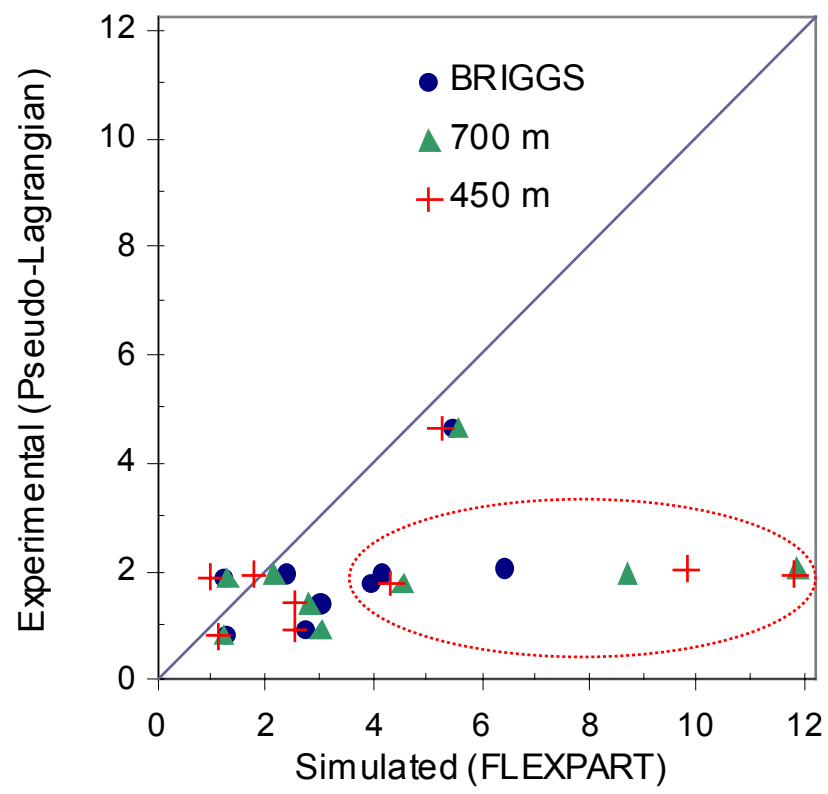

Fig. 7. Comparison between simulated and measured horizontal diffusion for the three different emission schemes performed during the dispersive simulations for equivalent temporal periods. Uncorrelated data (boldface numbers in Table 1) are included in a circle and correspond to transitional periods in the wind and turbulence fields.

migations" described, e.g., by Munn (1966). Additionally, during the plume-reorganisation phase, while a new "organised" plume is being formed and integrally advected in a new direction, "parts" of the "old" plume (emitted minutes and even hours before this new dispersive scenario) can return towards the emission area (if the wind field changes around $180^{\circ}$, as is the case in typical breeze dynamics), contributing to the aforementioned convective fumigation (Fig. 6), as previously observed by Millan (1987) in the Great Lakes area of Canada. This image of plume dynamics explains why fumigations from tall chimneys on complex terrains can produce strong fumigations in different directions and distances from the emission point simultaneously (as systematically monitored). This kind of dispersive scenario is associated with relatively short time periods, with very intense fumigations on areas very near the chimney (between 3 and $15 \mathrm{~km}$ for the case of this power plant).

During the late afternoon, the reorganisation and formation of a "new" organised plume takes place over progressively colder ground (favouring the development of ground inversions which decouple the plume aloft from the ground). Under such a dispersive scenario, the plume remains aloft and shows no impacts near the chimney. Moreover, as the ground inversion decouples orographic effects and wind field aloft, this transitional period tends to be shorter than the 
(a)

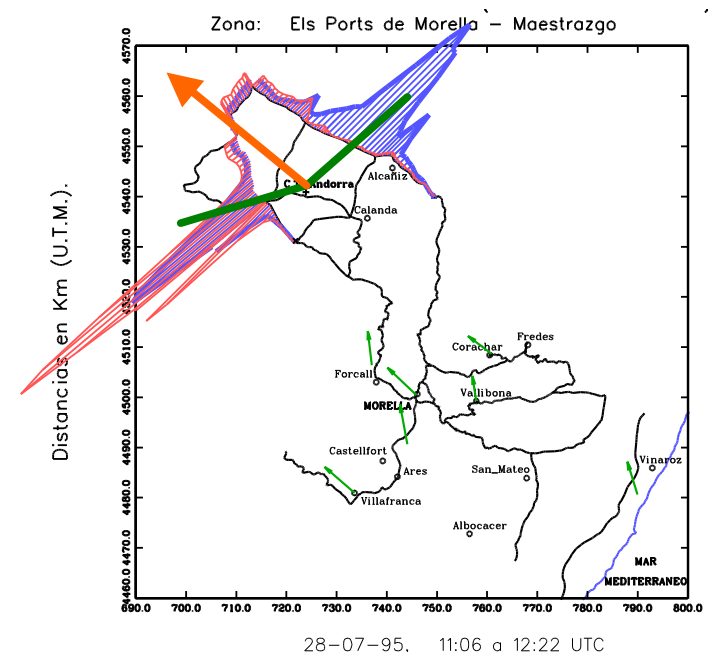

(b)

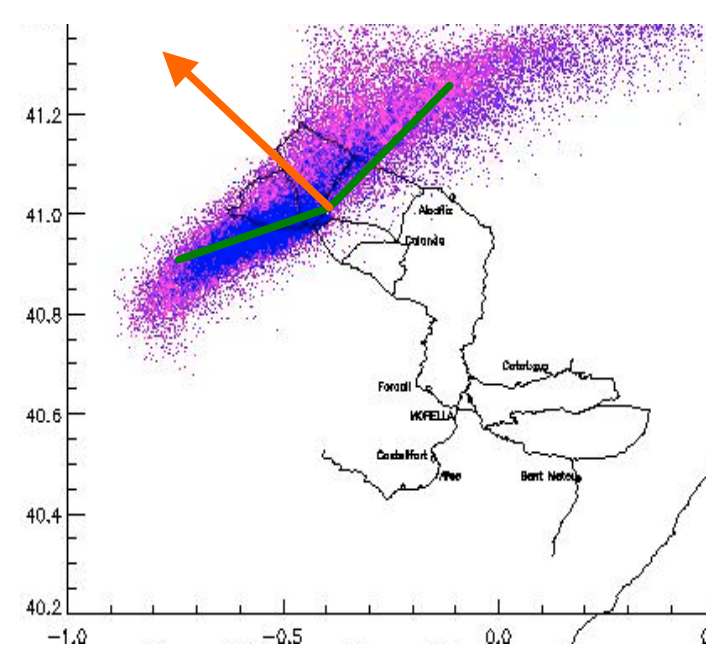

Fig. 8. (a) Measurements along a road network around a Power Plant plume in the interior of the Iberian Peninsula (Palau et al., 2006). The blue line shows the $\mathrm{SO}_{2}$ distribution aloft (measured with a remote sensor COSPEC). The red line shows simultaneous $\mathrm{SO}_{2}$ impacts on the ground. (b) Dispersive simulation showing the mesoscale-forced integral advection perpendicular to the axis defined by the simulated pollutant distribution aloft. Green line, symmetry axis defined by the pollutant distribution aloft; orange vectors, direction of the mean integral advection (average transport direction) of the plume aloft.

morning one. Under these dispersive conditions, the new plume aloft frequently aligns with the drainage winds following the Ebro valley axis towards the Mediterranean Sea and maintains a steady state during the whole night (Palau, 2003).

The aforementioned complex concatenated sequence of non-stationary dispersive scenarios, that are in constant transition because they are driven dynamically by the development of three-dimensional wind-fields at local-to-regional scales, is responsible for the observed multimodal distribution of pollutants around the emission sources as the plumes aloft reorganise and realign with the wind flow present during the day.

\section{Conclusions}

The availability of measurements aloft, obtained by means of a vehicle equipped with a remote sensor, enabled us to make a direct comparison between the experimental dispersion parameters and the simulated ones. This represents a clear advantage over the information provided by fixed ground-level monitoring stations for atmospheric pollutant control.

The model was able to reproduce the typical stationary dispersion scenarios (experimentally characterised with the COSPEC), although a significant temporal delay was detected between the simulation and the experimental measurements of the plume dispersion.
On the other hand, during the transition from one dispersion scenario to another, a significant discrepancy is detected between the experimental values of the plume concentration horizontal distribution (Sigma-y, defined from the transversal axis to the average transport direction) and the values obtained from the model (Table 1 and Fig. 7). In these situations, with no defined transport direction and, consequently, with transitory wind and turbulence fields, classical dispersion parameters lose their physical meaning.

During these transitional periods, the variability in plume horizontal distribution with emission height and the discrepancy with experimental data on the ground (hourly groundlevel concentrations) are evidence of the strong dependence of dispersion on the vertical distribution of momentum in the lower layers of the troposphere. Thus, during these transitional periods, the simulated plume dynamics may be strongly determined both by the order of the turbulence parameterisation schemes and by the land-use database used in the models. Further studies are needed to evaluate the effect of different model configurations and initialisations when simulating dispersive scenarios under transitional periods of this type.

The modelling approach proposed here is physically consistent with the observed processes and avoid the misfits of models based on classical dispersion parameters under transitional periods. The proposed system is more expensive than classical models in terms of computing power, but current advances in computer science allow it to be used at an affordable cost. 
Acknowledgements. The CEAM Foundation is supported by the Generalitat Valenciana and BANCAIXA (València, Spain). The authors would like to acknowledge the people from the CEAM Foundation who participated in the field measurement campaign. J. Scheiding's corrections of the English text are appreciated. We are grateful to Joaquín Meliá and Demetrio Segarra (Universitat de València, Spain) for their comments and encouragements. This study has been partially funded by the Conselleria de Territori i Habitatge (Generalitat Valenciana, SPAIN); by the Ministerio de Educación y Ciencia, research projects "TRANSREG www.ceam.es/transreg" (CGL2007-65359/CLI) and "GRACCIE" (CSD2007-00067, Programa CONSOLIDER-INGENIO 2010), and by the EU-funded Network of Excellence ACCENT (GOCECT-2004-505337). Results obtained will contribute to the EU action COST 728.

Edited by: W. E. Asher

\section{References}

Briggs, G. A.: Plume rise predictions, in: Lectures on Air Pollution and Environment Impact Analysis, Am. Meteorol. Soc., Boston, USA, 55-111 1975.

Grell, G. A., Dudhia, J., and Stauffer, D. R.: A description of the fifth-generation Penn State/NCAR mesoscale model (MM5), NCAR/TN-398+STR, 138 pp., 1994.

Hurley, P. and Physick, W.: A Lagrangian particle model of fumigation by breakdown of the nocturnal inversion, Atmos. Environ., 25A(7), 1313-1325, 1991.

Kalnay, E., Kanamitsu, M., Kistler, R., and collaborators: The NCEP/NCAR 40-year reanalysis project, Bull. Am. Meteorol. Soc., 77, 437-471, 1996.

McNider, R. T., Moran, M. D., and Pielke, R. A.: Influence of diurnal and inertial boundary-layer oscillations on long-range dispersion, Atmos. Environ., 22(11), 2445-2462, 1988.

Millan, M. M., Gallant, A. J., and Turner, H. E.: The application of correlation spectroscopy to the study of dispersion from tall stacks, Atmos. Environ., 10, 499-511, 1976.

Millan, M. M., Mantilla, E., Salvador, R., Carratalá, A., Sanz, M. J., Alonso, L., Gangoiti, G., and Navazo, M.: Ozone cycles in the western Mediterranean basin: interpretation of monitoring data in complex coastal terrain, J. Appl. Meteorol., 39(4), 487-507, 2000.

Millan, M. M., Salvador, R., Mantilla, E., and Kallos, G.: Photooxidant dynamics in the Mediterranean basin in summer: Results from European research projects, J. Geophys. Res., 102, 88118823, 1997.

Millan, M. M.: The regional transport of tall stack plumes, in: Regional and Long-range Transport of Air Pollution, edited by: Sandroni, S., Elsevier Science Publishers, Amsterdam, The Netherlands, 249-280, 1987.

Millan, M. M., Artiñano, B., Alonso, L., Navazo, M., and Castro, M.: The effect of meso-scale flows on regional and long-range atmospheric transport in the Western Mediterranean Area, Atmos. Environ., 25A(5/6), 949-963, 1991.
Munn, R. E.: Descriptive Micrometeorology, Academic Press, New York, 245 pp., 1966.

Palau, J. L., Pérez-Landa, G., Diéguez, J. J., Monter, C., and Millán, M. M.: The importance of meteorological scales to forecast air pollution scenarios on coastal complex terrain, Atmos. Chem. Phys., 5, 2771-2785, 2005, http://www.atmos-chem-phys.net/5/2771/2005/.

Palau, J. L., Pérez-Landa, G., Meliá, J., Segarra, D., and Millán, M. M.: A study of dispersion in complex terrain under winter conditions using high-resolution mesoscale and Lagrangian particle models, Atmos. Chem. Phys., 6, 1105-1134, 2006, http://www.atmos-chem-phys.net/6/1105/2006/.

Palau, J. L.: Atmospheric dispersion of a tall-stack plume on complex terrain (Dispersión atmosférica de las emisiones de una chimenea alta en terreno complejo), PhD Thesis, University of Valencia (Spain), edited by: CEAM Foundation, 366 pp., 2003 (in Spanish).

Palau, J. L., Meliá, J., Segarra, D., Pérez-Landa, G., Santa-Cruz, F., and Millán, M. M.: Seasonal differences in $\mathrm{SO}_{2}$ ground-level impacts from a power plant plume on complex terrain, Environ. Monit. Assess., online: http://www.springerlink.com/content/ rk748625120x8210/, doi:10.1007/s10661-008-0221-x, 2008.

Pérez-Landa, G., Ciais, P., Sanz, M. J., Gioli, B., Miglietta, F., Palau, J. L., Gangoiti, G., and Millán, M. M.: Mesoscale circulations over complex terrain in the Valencia coastal region, Spain Part 1: Simulation of diurnal circulation regimes, Atmos. Chem. Phys., 7, 1835-1849, 2007a, http://www.atmos-chem-phys.net/7/1835/2007/.

Pérez-Landa, G., Ciais, P., Gangoiti, G., Palau, J. L., Carrara, A., Gioli, B., Miglietta, F., Schumacher, M., Millán, M. M., and Sanz, M. J.: Mesoscale circulations over complex terrain in the Valencia coastal region, Spain - Part 2: Modeling $\mathrm{CO}_{2}$ transport using idealized surface fluxes, Atmos. Chem. Phys., 7, 1851$1868,2007 b$, http://www.atmos-chem-phys.net/7/1851/2007/.

Schumann, U.: Large-eddy simulation of turbulent diffusion with chemical reactions in the convective boundary layer, Atmos. Environ., 23, 1-15, 1989.

Stauffer, D. R. and Seaman, N. L.: Multiscale four-dimensional data assimilation, J. Appl. Meteorol., 33, 416-434, 1994.

Stohl, A., Forster, C., Frank, A., Seibert, P., and Wotawa, G.: Technical note: The Lagrangian particle dispersion model FLEXPART version 6.2, Atmos. Chem. Phys., 5, 2461-2474, 2005, http://www.atmos-chem-phys.net/5/2461/2005/.

Uliasz, M.: Lagrangian particle modeling in mesoscale applications, in: Environmental Modeling, Vol. II, edited by: Zannetti, P., Computational Mechanics Publications, 71-102, 1994.

Willmott, C. J.: On the validation of models, Phys. Geogr., 2(2), 184-194, 1981.

Zhang, D. and Anthes, R. A.: A high-resolution model of the planetary boundary layer - Sensitivity tests and comparisons with SESAME-79 data, J. Appl. Meteorol., 21, 1594-1609, 1982. 